\section{The 5 '-end polymorphism of the aldose reductase gene is not associated with diabetic nephropathy in Caucasian Type I diabetic patients}

Dear Sir,

Diabetic nephropathy (DN) is a major cause of morbidity and premature mortality in patients with Type I (insulin-dependent) diabetes. It is unclear how raised blood glucose concentrations predispose to diabetic nephropathy, although increased metabolism through the polyol pathway is a possible mechanism [1]. This could induce a cascade of metabolic abnormalities culminating in hypoxia and tissue ischaemia. Recent studies have suggested that the dinucleotide repeat polymorphic marker in the $5^{\prime}$-promoter region of the gene encoding aldose reductase $(A L R 2)$ may confer susceptibility to microvascular disease[2,3]. We investigated whether the $5^{\prime}$ ALR2 microsatellite marker could be used as a genetic marker for susceptibility to diabetic nephropathy by analysing 442 Caucasians with Type I diabetes.

We examined three cohorts of Type I diabetic patients: 211 with DN, 102 recently diagnosed Type I diabetic patients (sporadic or SPD) and 129 with long-term diabetes and no nephropathy (LTNN). The criteria used to classify patients have been described previously [4]. After DNA amplification using the polymerase chain reaction, each sample was size-fractionated with the ABI 377 Sequencer using the Genescan software (Perkin Elmer Ltd, North Cheshire, UK) and genotyped using the Genotyper software (Perkin Elmer Ltd).

Nine alleles Z-8, Z-6, Z-4, Z-2, Z, Z + 2, Z + 4, Z + 6 and $Z+8$, were detected (Table 1 ). No significant difference was seen in the allele frequencies between the DN and the SPD groups $\left(\chi^{2}=6.668,6 d f, p=0.354\right)$ nor between the $\mathrm{DN}$ and LTNN groups $\left(\chi^{2}=1.475,6 d f, p=0.961\right)$. Specifically, no significant difference was seen in the frequency of the two alleles reported to be associated with $(Z-2)$ and protective against $\left(Z+2\right.$ allele) DN. The frequency of the $5^{\prime}-A L R 2$ genotypes also showed no significant differences between the three groups.

Recently, a study of the 5 '-ALR2 microsatellite in patients with Type I diabetes suggested that subjects with a $Z-2$ allele are at a high risk for DN whilst the $Z+2$ allele seemed to be protective [2]. The $Z-2$ allele was also reported to be associated with early onset retinopathy (with or without DN) in a population of Chinese Type II (non-insulin-dependent) diabetic patients [3]. Association of the same $5^{\prime}-A L R 2$ allele with two microvascular complications (and in two types of diabetes) appears to enhance the validity of this finding. Although retinopathy and nephropathy are classified as microvascular diseases, the natural history of these complications is very different. DN affects between $30-40 \%$ of Type I diabetic patients with a peak incidence at 15-16 years of diabetes duration; thereafter, the incidence declines rapidly. In contrast, background diabetic retinopathy is duration-dependent and is found in almost all patients after 15 years of diabetes [5]. Proliferative retinopathy also increases with disease duration and, after an initial lag period, develops at the constant rate of $3 \%$ in previously unaffected patients per year [5] This variance in the natural history of diabetic complications is generally thought to reflect differences rather than similarities in their underlying pathogenic aetiologies (and these may be genetic or environmental).

Corresponding author: Dr P.H. Dyer, Diabetes Centre, Heartlands Hospital, Bordesley Green East, Birmingham B9 5SS
Table 1. Frequency (percentage) of $5^{\prime}$-ALR 2 microsatellite alleles in the three patient cohorts

\begin{tabular}{lccc}
\hline & $\begin{array}{l}\text { LTNN } \\
\%(n)\end{array}$ & $\begin{array}{l}\text { Nephropathy } \\
\%(n)\end{array}$ & $\begin{array}{l}\text { Sporadic } \\
\%(n)\end{array}$ \\
\hline Allele & & & \\
$Z-8$ & $0(0)$ & $0.47(2)$ & $0(0)$ \\
$Z-6$ & $1.55(4)$ & $1.66(7)$ & $0(0)$ \\
$Z-4$ & $6.20(16)$ & $7.34(31)$ & $9.31(18)$ \\
$Z-2$ & $37.21(96)$ & $36.56(150)$ & $34.80(72)$ \\
$Z$ & $39.15(101)$ & $36.73(155)$ & $38.73(79)$ \\
$Z+2$ & $12.02(31)$ & $12.80(54)$ & $11.76(24)$ \\
$Z+4$ & $2.71(7)$ & $3.32(14)$ & $4.41(9)$ \\
$Z+6$ & $1.16(3)$ & $1.89(8)$ & $0.49(1)$ \\
$Z+8$ & $0(0)$ & $0.24(1)$ & $0.49(1)$ \\
Total of & 258 & 422 & 204 \\
chromosomes & & & \\
\hline
\end{tabular}

It is of note that a comparison between the DN patients reported in a study [2] and those in our study (both selected from the UK population) shows no significant differences in the 5 'ALR2 microsatellite allele frequency $\left(\chi^{2}=4.334,8 d f\right.$, $p=0.83$, our calculation). Indeed, frequencies of the $Z-2$ allele ( $32 \%$ vs $35.6 \%)$ and the $Z+2$ allele $(12.7 \%$ vs $12.8 \%$ ) are remarkably similar in the two series. Furthermore, the DN subjects in that study did not differ from the group of non-diabetic control subjects and the relevant findings emerge by comparison with a group of 38 patients with diabetes of long-duration and no evidence of retinopathy or proteinuria. This is a small cohort for association analysis and may represent an unusual group of patients given the lack of pronounced retinopathy after this duration of diabetes. We would suggest, therefore, that the differences between the two United Kingdom studies do not specifically relate to diabetic nephropathy and that both data sets are consistent with regards to this complication. More recently, three further studies have looked at $5^{\prime}$ ALR2 microsatellite in diabetic nephropathy. One found no association between any of the alleles and nephropathy or retinopathy although ALR2 protein content was increased in patients with nephropathy [6]. Similarly, another study found no association between the $Z-2$ allele and nephropathy in another Type II cohort [7]. In contrast, the third study showed increased expression of the ALR2 mRNA related to the presence of the $Z-2$ allele, this allele was also associated with diabetic nephropathy although the number of patients studied was small $(n=31)$ [8].

In conclusion, our data suggest that in the United Kingdom population the $5^{\prime}-A L R 2$ polymorphism has little use as a marker for diabetic nephropathy in Type I diabetes. Furthermore, our results imply that this locus is unlikely to have a significant role in the pathogenic aetiology of this complication. Examination of this locus using intrafamilial association studies (such as the transmission disequilibrium test) will be required to definitively exclude a minor effect on the genetic susceptibility to DN.

Acknowledgements. We acknowledge the assistance of Dr S. Kumar, Dr S.L.C. Gough, Dr S.P. Gibson, B. R. Rowe, Dr P.R. Smith, Dr S.J. Davies, Dr S.M. Marshall, Professor A. J. M. Boulton, Mr P. J. Morris and Professor J. A. Todd.

Yours sincerely,

P.H.Dyer, T.A.Chowdhury, M.J.Dronsfield, D.Dunger, A. H. Barnett, S.C. Bain 


\section{References}

1. Cohen M (1986) Aldose reductase, glomerular metabolism, and diabetic nephropathy. Metabolism 3: 55-59

2. Heesom AE, Millward A, Demaine AG (1997) Polymorphism in the $5^{\prime}$-end of the aldose reductase gene is strongly associated the development of diabetic nephropathy in type I diabetes. Diabetes 46: 287-291

3. Ko BCB, Lam KSL, Wat NMS, Chung SSM (1995) An (AC)n dinucleotide repeat polymorphic marker at the $5^{\prime}$ end of the aldose reductase gene is associated with early -onset diabetic retinopathy in NIDDM patients. Diabetes 44: 727-732

4. Chowdhury TA, Kumar S, Gough SLC et al. (1996) Examination of two genetic polymorphisms within the renin- angiotensin system: no evidence for an association with nephropathy in IDDM. Diabetologia 39: 1108-1114
5. Klein R, Klein BE, Moss SE (1989) The Winconsin Epidemiology Study of Diabetic Retinopathy: a review. Diabetes Metab Rev 5: 559-570

6. Maeda S, Haneda M, Yasuda H et al. (1999) Diabetic nephropathy is not associated with the dinucleotide repeat polymorphism upstream of the aldose reductase (ALR2) gene but with erythrocyte aldose reductase content in Japanese subjects with type 2 diabetes. Diabetes 48: 420-422

7. Moczulski DK, Doria A, Zychma M, Zukowska-Szczechowska E, Warram JH, Grzeszczak W (1999) The role of the aldose reductase gene in the susceptibility to diabetic neohropathy. Diabetologia 42: 94-97

8. Shah VO, Nikolic J, Sun Y et al. (1998) Z-2 microsatelitte allele is linked to increased expression of the aldose reductase gene in diabetic nephropathy. J Clin Endocrinol Metab 83: 2886-2891

\section{The inhibition of glycogen synthesis by fatty acids is not mediated by inhibition of extracellular signal-regulated kinase 1/2}

\section{Dear Sir,}

Insulin is a multi-functional hormone that activates several intracellular signalling pathways. After initiation of insulin receptor autophosphorylation, a signalling cascade ensues, including phosphorylation of IRS-1 and IRS-2, activation of PI3 kinase and phosphorylation of extracellular signal-regulated kinase 1/2 (mitogen activated protein kinase). Usui et al. [1] presented data to suggest that NEFA inhibit insulin-stimulated activation of extracellular signal-regulated kinase $1 / 2$ and proposed that this was responsible for the negative effects of NEFA on insulin action. To examine effects of individual fatty acids on insulin signalling, we attempted to replicate the findings in an identical cell line; HIR (rat-1 fibroblast, overexpressing the human insulin receptor, a gift of D. McClain, University of Mississippi Medical Center, [2])

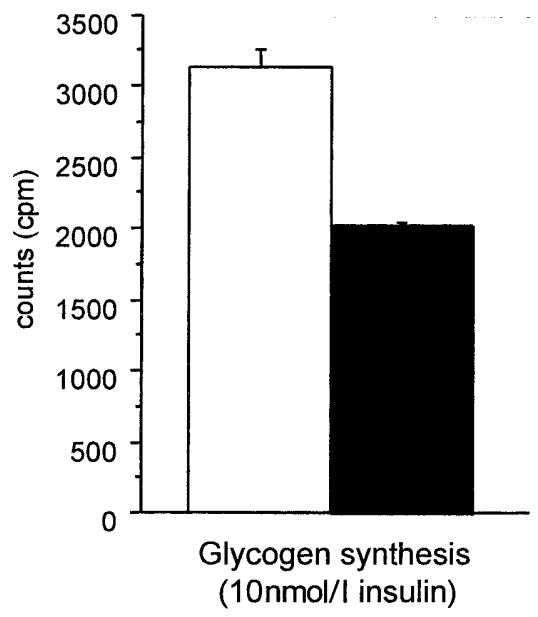

Fig. 1. Palmitate inhibits glycogen synthesis at $10 \mathrm{nmol} / \mathrm{l}$ insulin. $\square$ BSA $\square$ Palmitic acid/BSA

Corresponding author: S. R. Smith, MD, Experimental Endocrinology Laboratory, Pennington Biomedical Research Center, 6400 Perkins Road, Baton Rouge, LA 70808, USA
The expected inhibition of glycogen synthesis was observed when the cells were pre-incubated with $1 \mathrm{mmol} / \mathrm{l}$ palmitate for $2 \mathrm{~h}$ and palmitate was included during incubation with insulin $[3,4]$, (Fig. 1). On the other hand, under identical pre-incubation conditions, insulin-stimulated extracellular signal-regulated kinase $1 / 2$ phosphorylation was similar in the control and palmitate-treated cells when observed with an antibody specific for the phosphorylated form of extracellular signal-regulated kinase 1/2 (Fig. 2A), (NEB, Beverly, Mass. USA). Quantitative scanning of the $\mathrm{x}$-ray film showed no differences between control cells and cells pre-treated with palmitate (data not shown). Figure $2 \mathrm{~B}$ shows equal loading on the gel by an antibody specific

\section{insulin}

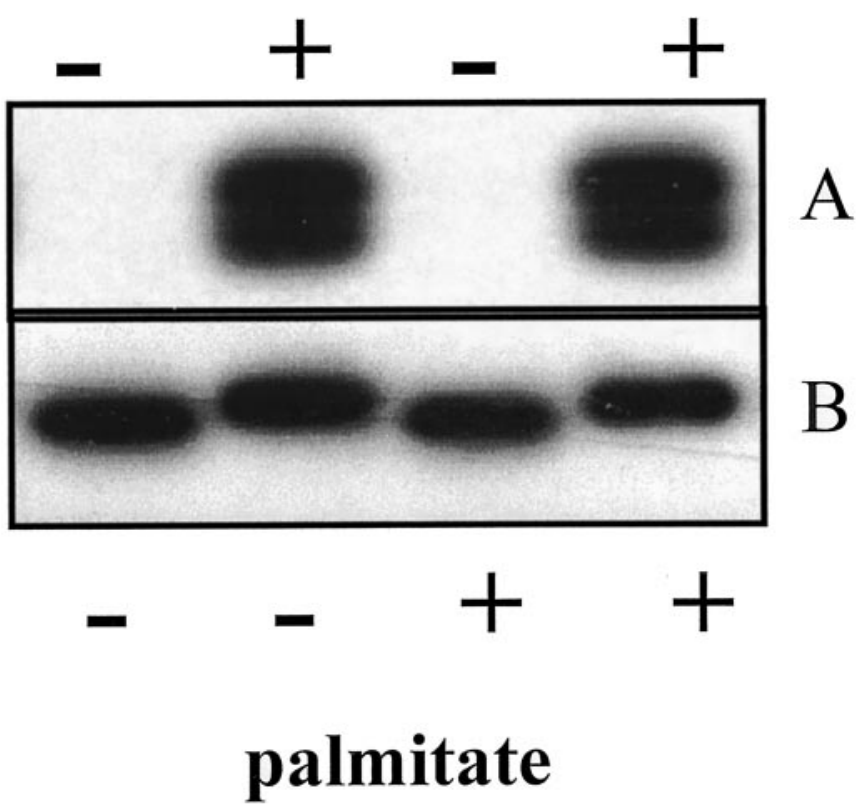

Fig. 2 A, B. Insulin stimulated activation of ERK1/2 in the presence and absence of insulin. Figure $2 \mathbf{A}$ is a representative blot using an anti phospho-specific antibody. Figure $2 \mathbf{B}$ is the same samples probed with an antibody which reacts with both phosphorylated and non-phosphorylated ERK1/2 showing equal loading of ERK1/2 on the gel 